\title{
К ВОПРОСУ ОБ ОСОБЕННОСТЯХ И КУЛЬТУРНОЙ ЦЕННОСТИ ИЗОБРАЗИТЕЛЬНОГО ИСКУССТВА МАЛЫХ ЭТНОСОВ, ЗАНИМАЮЩИХСЯ ЛЕСНОЙ ОХОТОЙ В БАССЕЙНЕ РЕКИ АМУР 1
}

\section{ON THE PECULIARITIES AND CULTURAL VALUE OF THE FINE ARTS OF SMALL ETHNIC GROUPS ENGAGED IN FOREST HUNTING IN THE AMUR RIVER BASIN \\ Fu Zhongfeng Jiang Dongmei}

Summary: The purpose of this article is to characterize the fine arts of small ethnic groups engaged in forest hunting in the Amur River basin. The author of the work pays special attention to the nature of the national cultures of the three tribes (Evenks, Daur and Ooken), which has a number of individual differences in the ethnicity of the carriers, but at the same time reveals universal features dictated by the general living conditions, way of life and religion of the representatives of all three considered small nationalities. The article concludes that the study and popularization of the peculiarities of the visual arts of hunters in the Amur region will have a positive impact on the preservation of consistency in the study of issues of Chinese culture in general.

Keywords: small ethnos, fine arts, peoples of the Amur river basin, Evenks, Ooken, Daur, forest hunter culture, Chinese fine arts.

\author{
Фу Чжунфэн \\ Професссор, Хэйхэский университет, провинция \\ Хэйлунцияна, КНР \\ fzfart@vip.q9.com \\ Цзян Дунмэй \\ Старший преподаватель, Хэйхэский университет, \\ провинция Хэйлунцияна, КНР \\ 174580767@qq.com
}

Аннотация: Целью настоящей статьи является характеристика изобразительного искусства малых этносов, занимающихся лесной охотой в бассейне реки Амур. Автором работы обращено особое внимание на природу национальных культур трех племен (эвенков, даур и орокенов), которая имеет ряд индивидуальных различий по этнической принадлежности носителей, но в то же время обнаруживает универсальные черты, продиктованные общими условиями жизни, бытом и религией представителей всех трех рассматриваемых малых народностей. В статье сделан вывод о том, что изучение и популяризация особенностей изобразительного искусства охотников Приамурья окажет положительное влияние на сохранение системности в исследовании вопросов китайской культуры в целом.

Ключевые слова: малый этнос, изобразительное искусство, народности бассейна реки Амур, эвенки, орокены, дауры, культура лесных охотников, китайское изобразительное искусство.
$\mathrm{M}$ алый этнос - лесные охотники, проживающие в бассейне реки Амур, - является важной частью китайской нации в целом. В ходе многолетней производственной практики и длительного процесса развития народности сформировалась своеобразная культурная система с уникальными национальными чертами и региональными особенностями. Одним из таких специфических признаков рассматриваемого малого этноса оказывается изобразительное искусство.

Образ жизни лесных охотников имеет сходство с тем, который присущ кочевым народам, что неизбежно находит своё художественное воплощение в особенностях культуры и языках малого этноса. Поэтому образ жизни охотников стал главной характеристикой национальной идентичности исследуемого социума, ведущего свою практическую деятельность в бассейне реки Амур.

Рассмотрим конкретные примеры. Одними из пред- ставителей малых народностей, занимающихся лесной охотой, оказываются эвенки. Олень занимает важное место в развитии названной народности, что и определило статус данного животного в качестве эвенкийского символа [2]. Как единственная этническая группа в Китае, которая разводит и использует в хозяйственной деятельности оленей, народ эвенки особенно трепетно относится к этим животным (неслучайно существует ещё одно «неофициальное» наименование данного этноса «племя оленей»). Как тотемный символ олень широко используется в различных изобразительных искусствах. Например, его изображение встречается на этнических костюмах, в орнаментах и узорах, и даже резьба по дереву, кости и изделия из кожи также нередко сопровождаются иллюстрированием главного зооморфного символа народности. В ходе длительного художественного развития родилось большое количество различных способов отображения оленя, таких как силуэт, абстракция, рисование линий, и т.д. 
Кроме того, ещё одним символом этнических меньшинств бассейна Амура является белая береза. Это разновидность лиственного дерева с чрезвычайно высокой способностью приспосабливаться к внешним условиям, что позволяет назвать данное дерево особенно «живучим». Это одна из основных пород деревьев в горах Большого Хингана. Лесные охотники, в частности народность орокены, испытывают особые чувства к березам, что также сформировало уникальные особенности в области традиционной культуры данного этноса. Берестяная культура является национальной символикой, существует множество видов изделий из бересты, таких как лодки, чаши, шкатулки и т. д. Береста также является важнейшим материалом пластического искусства: представители орокенов широко используют иглы из костей животных для гравировки узоров.

Этносы, занимающиеся лесной охотой в бассейне реки Амур, являются многоэтническими племенами. Племена эвенков, даур и орокенов имеют тесные взаимоотношения, которые возникли и укрепились в течение длительного периода их культурного развития, в частности за счёт развития торговых отношений между народностями. И сходства эти проявляются в том числе и на культурном уровне. Изобразительное искусство народностей, занимающихся лесной охотой, имеет ярко выраженный национальный характер. На макроуровне художественное искусство лесных охотников бассейна реки Амур имеет кардинальные отличия от искусства других китайских этнических общностей. Однако на микроуровне, лесная охота как ведущий вид практической деятельности объединяет несколько малых народностей, в изобразительном искусстве которых также наблюдаются определенные различия. Это объясняется несколькими факторами. Во-первых, с макроэкономической точки зрения, все три охотничьи этнические группы произошли от этнической группы сяньбэй (обитавшие на территории Центральной и Восточной Азии [1, с. 321]) и, соответственно, имеют определенное кровное родство. Среди них этнические группы эвенков и орокенов долгое время были одной и той же этнической группой. 70\% их этнических языков почти одинаковы. Симптоматично, что они имеют некоторое сходство в изобразительных искусствах и даже в национальной культуре. Кроме того, все три вышеупомянутые этнические группы верят в шаманизм. Религиозная культура, соответственно, также оказало влияние на особенности национального характера, а следовательно, и на изобразительное искусство. Во-вторых, с микроскопической точки зрения, хотя народы, охотящиеся в лесах бассейна реки Амур, живут в непосредственной близости друг к другу, их территории обитая имеют различия: большинство эвенков живут в горах, в то время как орокены в основном населяют склоны гор, дауры - на предгорьях. Таким образом, условия обитания обусловливают тот факт, что эвенки и орокены занимаются перегоном скота, а на- род даур - сельскохозяйственной практикой. Различные методы производства являются основными факторами, оказывающими огромное влияние на формирование национальной культуры. Приведём в пример архитектуру этносов. Здания, сооружаемые эвенками и орокенами обнаруживают сходства, в том числе и потому, что являются жилищами кочевников, в то время как архитектурное моделирование даур представляет собой традиционную центральную ось, которая является типичным символом земледельческого этноса.

Народы, занимающиеся лесной охотой в бассейне реки Амур, связаны культурно, и наиболее важным из них является общность веры. Шаманизм - примитивная религия, сформированная на основе народных верований. Он широко популярен на северо-востоке и даже северо-западе Китая. Однако особо широкое распространение получил в среде охотников. Одни и те же религиозные верования определяют наличие схожих черт в изобразительном искусстве рассматриваемых этнических групп, в том числе и на религиозное искусство. Жертвоприношения шаманизма являются наиболее торжественными действиями всех трех народностей. Одной из отличительных черт шаманских ритуалов жертвоприношения - это обязательное ношение шаманских костюмов во время самой церемонии [3]. Однако следует отметить, что состав и оформление шаманских костюмов у разных этнических групп отличается: в шаманских костюмах эвенков присутствуют «шляпы богов», а также священная специфическая одежда, маски и т.д. Священная шляпа - самая важная часть костюма эвенкийского шамана: она имеет форму двойных рогов. Наличие данного элемента в предмете ритуальной одежды обусловлено тем, что в сознании представителей названного этноса боги живут на возвышенностях: горных вершинах, кронах деревьев. Кроме того, рога северного оленя - главного символа этноса - устремлены вверх, подобно ветвям деревьев, и в силу особого отношения людей к этому животному являются божественными.

Этническое название костюмов даурских шаманов «каменные доспехи Сама». Они относятся к костюмам, используемым в крупномасштабных этнических церемониях, в частности, в целительских обрядах. Они состоят из мантий, жилетов богов. Что касается костюмов, то шаманские костюмы изготавливаются более изощренно. Все платья, шали и ленты имеют разный цвет фона и расшиты цветами, птицами, рыбами и животными с использованием характерных религиозных оттенков.

Отдельно следует сказать и о воплощении национальной эстетической ценности в искусстве рассматриваемых этнических групп.

Как особая этническая группа племен, люди, охотящиеся в лесах бассейна реки Амур, имеют совершенно 
особую культуру, следовательно, и формы выражения, и характеристики изобразительного искусства оказываются продиктованными особенностями национальной культуры народности.

Хэйлунцзян - приграничная провинция на северовостоке Китая. Он всегда был важным поселением этнических меньшинств. Большое количество северных кочевников живут в бассейне реки Амур. Они внесли огромный вклад в формирование и развитие региональной культуры Хэйлунцзяна. Этническая группа лесных охотников бассейна реки Амур является важным участником формирования региональной культуры провинции Хэйлунцзян. Ее изобразительное искусство имеет характеристики национальной и религиозной идентичности. Данный факт находит своё подтверждение в наличии характерных узоров, украшений, качественном составе эксплуатируемых материалов. Например, современное искусство характеризуется широким использованием различных узоров и орнаментов, а также украшений, связанных с национальными тотемами (этническими символами) и шаманизмом.
Таким образом, этническая идентичность изобразительного искусства этносов, занимающихся лесной охотой в бассейне реки Амур, чрезвычайно ярка и разнообразна. Национальное изобразительное искусство представителей охотничьих племен охватывает все аспекты жизни этноса. Кроме того, оно находится под сильным влиянием шаманизма. Не вызывает сомнения тот факт, что изобразительное искусство эвенков, даур и орокенов имеет важное эстетическое значение, позволяя рассматривать созданные ими образцы как органичную часть китайского искусства в целом, и как примеры воплощения национальной культуры, которая призвана подчеркнуть региональные культурные особенности названных племен. Более детальное изучение изобразительного искусства народностей, занимающихся лесной охотой в бассейне реки Амур, таким образом, позволит оказать необходимую поддержку на пути сохранения и популяризации культуры национальных меньшинств, что, несомненно, окажет положительное влияние на развитие и процветание национальной китайской культуры в целом.

\section{ЛИТЕРАТУРА}

1. Миклашевич Е.А. «Племя единорога» на Енисее (сяньбэйские мотивы в наскальном искусстве Минусинской котловины) // Изобразительные памятники: стиль, эпоха, композиции: Материалы тематической научной конференции. - СПб, 2004. - С. 320-325.

2. Туголуков В.А. Следопыты верхом на оленях / АН СССР; Предисл. канд. геогр. наук Е.Е. Сыроечковского; Отв. ред. д-р ист. наук В.А. Александров. М.: Наука, 1969. - 216 c.

3. Noll Richard, Kun Shi. The Last Shaman of the Oroqen People of Northeast China // Journal of Korean Religions, 2009. - Vol. 17. - No. 1-2. - P. 117-140. 